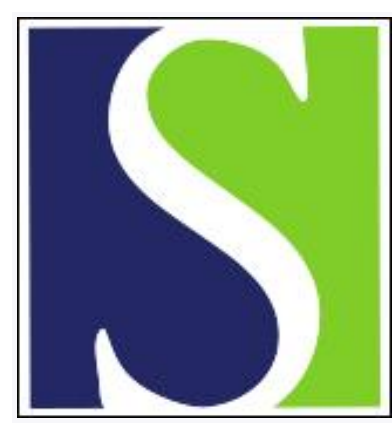

Scand J Work Environ Health 1994;20(6):393-400

https://doi.org/10.5271/sjweh.1382

Issue date: 01 Dec 1994

Effectiveness of and compliance to preventive measures against the occupational transmission of human immunodeficiency virus.

by Roy E, Robillard P

Affiliation: Centre for AIDS Studies, Montreal General Hospital, Canada.

This article in PubMed: www.ncbi.nlm.nih.gov/pubmed/7701284

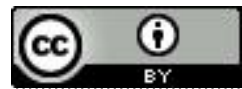




\title{
Effectiveness of and compliance to preventive measures against the occupational transmission of human immunodeficiency virus
}

\author{
by Élise Roy, MD, ${ }^{1}$ Pierre Robillard, $\mathrm{MD}^{2}$
}

\begin{abstract}
ROY É, ROBILLARD P. Effectiveness of and compliance to preventive measures against the occupational transmission of human immunodeficiency virus. Scand J Work Environ Health 1994;20: $393-400$

To prevent the occupational transmission of human immunodeficiency virus (HIV) and other bloodborne infections in health care settings, guidelines have been issued as universal precautions and body substance isolation. Patient testing has also been advocated. The literature on the compliance to and effectiveness of these measures was reviewed and analyzed to establish the state of knowledge and make appropriate recommendations to improve guidelines. It showed that workers' compliance to recommended measures is relatively poor. The effectiveness and cost-effectiveness of universal precautions and body substance isolation remain to be demonstrated. Testing patients for HIV infection and other bloodborne pathogens does not appear to be a more appropriate solution. Focus should be placed on preventing parenteral exposures and applying risk assessment methods to identify health care settings and procedures at higher risk. These measures would allow safer medical devices to be targeted and would ensure that financial resources would be available to implement appropriate preventive mea-
\end{abstract} sures.

KEY TERMS - body substance isolation, compliance, cost-effectiveness, health care worker, hepatitis $\mathrm{B}$, hepatitis C, risk assessment, universal precautions.

As of June 1993, 174 cases of occupational human immunodeficiency virus (HIV) infection had been reported among health care workers worldwide (112). Of these, 63 are documented seroconversions, meaning that the health care worker had a negative, postexposure HIV antibody test result and subsequently tested positive for HIV. The other 111 cases are considered to be probable occupational infections, as seroconversion was not documented and no other risk factors could be identified. The risk of occupational HIV infection following parenteral exposure to contaminated blood is estimated to be $0.3 \%$ (13). The risk of transmission resulting from exposure to mucous membranes or nonintact skin lesions is considered to be much lower, around $0.09 \%$ (14).

Other bloodborne pathogens are also at the origin of occupational infections, for example, the hepatitis $B$ virus, for which the risk of transmission following percutaneous exposure is estimated to be up to 100 times greater than that of HIV. Cases of hep-

\footnotetext{
' Centre for AIDS Studies, Montreal Public Health Unit, Montreal General Hospital, Montreal, Canada.

2 Direction of Public Health of Montreal, Occupational and Environmental Health Unit, Montreal, Canada.
}

Reprint requests to: Dr É Roy, Centre for AIDS Studies, Montreal Public Health Unit, Montreal General Hospital, 1616 René Lévesque Blvd West, $3^{\text {rd }}$ Floor, Montréal, Canada, H3H 1 P8. atitis $\mathrm{C}$ of occupational origin have also been reported $(15-20)$ and the risk of transmission following a parenteral exposure to contaminated blood, although not precisely quantified, could be as high as $10 \%(21)$.

Faced with these very serious infections, measures have been proposed to avoid transmission to health care workers, namely, universal precautions and body substance isolation. These two systems are based on the principle that all patients are considered to be infectious. This notion of universality constitutes a major change in the approach to preventing the transmission of bloodborne pathogens in health care settings that, until recently, was more selective, relying on the patient's presumed or established diagnosis. There is resistance to this change among health care workers, and some even suggest that the presence of infections should be actively sought out in all patients since knowledge that a patient is infected would allow health care workers to protect themselves better $(22,23)$. For example, in certain cases, a therapeutic decision could be changed when a patient is known to be infected so that alternatives that are safer for health care personnel could be prescribed.

This article examines the universal and selective approaches by reviewing the state of knowledge concerning worker compliance, and the effectiveness of both of these approaches in regard to the occupational transmission of HIV in the workplace. 


\section{Universal measures}

\section{Universal precautions}

Universal precautions were proposed by the Centers for Disease Control and Prevention to prevent bloodborne infections in health care settings $(24,25)$. The level of exposure to body fluids constitutes the main determinant of occupational risk of infection. Added to this concept is the principle of universality of risk, all patients being assumed to be infected.

Guidelines were issued regarding work practices, personal protective equipment (barriers), cleaning practices, disinfection and decontamination, and the manipulation and disposal of needles and sharp objects. These measures aim to prevent exposure to specific body fluids such as blood, semen, vaginal secretions, and any body fluid visibly contaminated with blood, as well as cerebrospinal fluid, synovial fluid, pleural fluid, peritoneal fluid, pericardial fluid, and amniotic fluid. Saliva is excluded except in the context of dental and oral procedures. In practical terms, the guidelines recommend the use of individual protective equipment, such as gloves, masks, protective eyewear, aprons, and gowns, to avoid exposure by direct contact or by splashes. To prevent injuries caused by needles or other sharp objects, needle recapping is proscribed and sharp objects must be disposed of in puncture-resistant containers.

\section{Compliance to universal precautions}

The degree of compliance by health care workers to some or all universal precaution measures was studied in different clinical settings. In a study of 806 observations made of 24 health care workers in emergency rooms, dental clinics, and plastic surgery clinics, $31.3 \%$ were compliant, $40.7 \%$ were partially compliant, and $28 \%$ were noncompliant (26). Use of puncture-resistant containers for the disposal of sharp objects was satisfactory, but needle recapping was still very prevalent and compliance to hand washing very low. Another study combining two methods, questionnaire and observation, found that universal precautions were followed in only $19 \%$ of the 1441 procedures observed (27). Compliance according to profession was $27 \%$ for nurses, $5 \%$ for laboratory technicians, and $3 \%$ for physicians. Compliance to procedures of safe pipetting $(97 \%)$ and the handling of needles (72\%) was good but dropped for hand washing $(28 \%)$ and the wearing of gloves (35\%). In $81 \%$ of the cases, physicians did not manipulate needles in compliance with recommendations. Discomfort, interference with procedures, forgetfulness, and lack of safety materials were the reasons most often listed for noncompliance to universal precautions.

Most studies evaluated only some of the measures proposed by universal precautions, particularly barrier methods such as use of gloves. According to their findings, the rate of glove use and the use of other barrier methods varied according to several parameters, mainly the profession, the clientele, and the type of procedure. Physicians (surgeons, specialists, generalists, residents, and medical students) used gloves much less than nurses, in a proportion varying from 10 to $40 \%$ for the former and 40 to $75 \%$ for the latter $(28-33)$. Swedish dentists with private practices used gloves during only $54 \%$ of their procedures, while those in public practice did so in $77 \%$ of the cases (34). Paramedics only rarely complied to the systematic use of barrier methods, the percentage of utilization varying from 8 to $37 \%(29,35)$.

As to the age of clientele, those treating children had a lower utilization rate $(29,32)$ than those treating patients $15-44$ years of age, who had the highest rate (29).

As to the type of procedure carried out, the rate of glove use among nurses varied from $70 \%$ for phlebotomy to $92 \%$ for arterial punctures (36). The use of barrier methods was $17 \%$ for major procedures, $56 \%$ for minor ones, $19 \%$ when the patient was bleeding, and $44 \%$ when the patient was not bleeding (29). The lack of easy access to protective methods in emergency situations could explain these surprising results, as suggested by a study showing that supplying protective equipment in readily available kits in strategic locations of emergency rooms had increased the use of universal precautions from 16 to $62 \%$ in a Florida hospital (37).

Compliance to the adequate handling and disposal of needles is generally higher than with barrier methods. A study showed that the manipulation of needles by emergency room residents was adequate in $97 \%$ of the cases at an American hospital (37). However, despite recommendations about needle recapping, it was observed that, in four Michigan hospitals, 8 to $51 \%$ of the needles found in containers had been recapped before disposal (38). The situation seems even worse for paramedics, who recapped needles in $78 \%$ of the cases (35), and for physicians who did so in a proportion varying from 50 to $60 \%$ (31).

Most of these studies were conducted with a questionnaire administered to workers, but one study using two methods, questionnaire and direct observation, showed that workers tended to overestimate their compliance to universal precautions (27). Nonetheless, the tendencies drawn from all the aforementioned studies are similar and show that compliance to recommendations relating to needle manipulation is higher than that relating to the use of barrier methods, that nurses are more compliant than physicians, and that access to, and the ease of use of, protective equipment well integrated into regular task performance tended to increase compliance. Furthermore, the notion of universality is still not well integrated since the potential risk presented by the patient is taken into consideration by health care workers in their decision to use preventive measures. 


\section{Effectiveness and cost of universal precautions}

Effectiveness studies. With respect to the effectiveness of universal precautions, a study targeted a cohort of health care workers participating in the United States National Institutes of Health (NIH) surveillance program of occupational exposures to HIV (39). Workers had to answer a questionnaire on cutaneous exposures sustained during the previous year. The analyses compared exposures before and after the implementation of universal precautions. The average annual number of exposures per worker dropped from 35.8 to 18.1 for blood $(\mathrm{P} \leq 0.001)$ and from 77.8 to 40.8 for other body fluids $(\mathrm{P} \leq 0.001)$.

Another study gathered data on physicians' exposures in hospital medical care units before and after the implementation of universal precautions. Everyday they had to answer a questionnaire on cutaneous and parenteral exposures sustained during the day (40). A global reduction in exposures of 5.07 to 2.66 per patient-month per physician, associated with an increase in aborted exposures from 3.41 to 5.90, was found. As for accidental needlesticks, the rate fell from 0.39 to 0.15 , but this difference was not statistically significant $(P=0.123)$. The methodological differences between these two studies and the absence of a reference group make it difficult to draw conclusions on the effectiveness of universal precautions.

Other authors have attempted to evaluate the effectiveness of certain components of universal precautions. For rigid containers, there was no reduction in the total number of needlesticks nor in the practice of recapping in association with their implementation $(41-44)$. Two of the studies $(41,42)$ showed however a reduction in needlesticks in relation to needle disposal, and one (45) reported a global reduction of all needlesticks, as well as those related to recapping among nurses.

Other studies have dealt with the effectiveness of using some barrier methods, such as gowns and surgical sheets (46-48). It was concluded that the effectiveness in preventing blood contact varied according to the type of material, its impermeability, and wear and tear.

Even if barrier methods such as gloves succeeded in reducing the number of cutaneous exposures $(39,40)$, their role in preventing the transmission of bloodborne pathogens among health care workers is not clear since needlesticks and cuts, which are not prevented by the use of gloves, present the greatest risk for the transmission of bloodborne infections.

Recent studies have been conducted with the purpose of evaluating new medical devices designed for preventing accidental needlesticks, such as selfresheathing needles, new connecting devices for intravenous lines or blunt suture needles. The results are promising and would allow immediate causes of exposures to be eliminated (ie, unnecessary needles or ill-conceived devices) $(49,50)$. Such an approach is complementary to the guidelines of the Centers for Disease Control and Prevention on universal precautions.

Cost and cost-effectiveness studies. An American study looked at the annual costs of implementing universal precautions in a 900-bed university hospital (51). The conclusion was an annual increase in costs of USD 350900 . However neither the effectiveness nor the benefits of universal precautions were evaluated. In a Canadian study the cost-effectiveness ratio of universal precautions in a 450-bed hospital was found to be CAD 128862000 per case of occupational HIV infection prevented, according to the authors' best-case estimate (52). It was concluded that universal precautions were not cost-effective and that priority should be put on the prevention of parenteral exposures, notably through a better design of materials and techniques used.

Despite the scarcity of studies on costs, universal precautions seem to constitute an expensive solution with to which prevent the occupational transmission of HIV. However direct and indirect costs of exposure to body fluids were ignored in the studies. These costs could be substantial, for example, those related to (i) reporting exposure, (ii) a 6- to 12 -month postexposure follow-up of workers possibly administering immunoglobulin or zidovudine, (iii) the loss of productivity associated with these visits, and (iv) the postexposure stress of workers awaiting their HIV antibody test results. Otherwise, preventing other bloodborne infections (hepatitis B and C) was not taken into account although it constituted another important parameter in the cost-effectiveness ratio equation. Indeed Stock et al found that universal precautions present a more interesting cost-effectiveness ratio when the risk of hepatitis B is considered, although vaccination is certainly the most effective preventive means for this infection (52).

\section{Body substance isolation}

The expression body substance isolation describes a system of prevention of nosocomial infections, including the transmission of occupational infections (53). Like universal precautions, this system is applied to all patients, regardless of their diagnosis. A major difference is that body substance isolation targets all body fluids and moist body substances. It includes six components (54), the following four of which are aimed at bloodborne infections: (i) gloves must be worn for all expected contact with a body substance, (ii) other barriers such as masks, glasses, gowns, and aprons must be worn when contamination of clothing or skin or splashes are anticipated, (iii) reusable items must be securely contained to prevent leakage, (iv) needles and other sharp objects must be disposed of in puncture-resistant containers; needles should not be recapped. There are few other differences with universal precautions, for example, 
with body substance isolation, the health care worker is called upon to judge the pertinence of using barrier methods such as wearing gloves during phlebotomy, a practice which is optional if the worker is experienced and does not deem it necessary (55).

Some have found that body substance isolation is easier to implement than universal precautions (56), but few studies have evaluated its application and effectiveness, particularly concerning bloodborne infections. In one study, an increase of 60 to $80 \%$ in adequate glove use was observed after body substance isolation was implemented, but adequate hand washing was not prevalent ( 30 to $45 \%$ ) (57). In a survey, despite adequate training and knowledge of the principles of body substance isolation, nearly half of the respondents frequently using needles recapped them occasionally or often. It can be concluded that, as for universal precautions, worker compliance to body substance isolation is not optimal (58).

\section{Selective measures}

As an alternative to universal approaches, identifying patients infected with HIV has been proposed so that supplemental preventive measures can be taken with these patients and their specimens (59-61). This proposition is in line with labeling infectious specimens to advise the worker to take appropriate preventive measures.

\section{Antibody testing for human immunodeficiency virus}

HIV-infected persons can be identified with a simple serological test. Current tests for HIV antibodies, including two immunoenzymatic tests (ELISA) followed by a more specific confirmation test, are very reliable (62). The high sensitivity and specificity of the test sequence allow virtual identification of all individuals (except those who are in the postinfection period) with a very low proportion of false positive results. The importance of quality control assuring the high specificity of confirmation tests must be emphasized because a lowering of specificity could actually compromise the predictive value of a positive result in populations in which the prevalence of infection is low.

Despite the good performance of the test, there is a delay for obtaining the result that could limit its widespread use, especially in emergency situations. The arrival on the market of rapid and effective tests with sensitivity and specificity approaching those of conventional techniques $(63,64)$ could be a solution to this problem. The utilization of these tests as diagnostic tools is not currently authorized in all countries.

Another aspect that cannot go unmentioned is that all persons undergoing an HIV antibody test must freely give their informed consent and receive appropriate counseling. The only exception to this rule of informed consent is in the case of blood, semen, and organ donations, for which HIV antibody testing is systematic. Upon nearing the end of the first decade of the HIV epidemic, however, what some call "HIV exceptionalism" could be challenged and therefore lead to less stringent rules on informed consent (65).

\section{Effectiveness and cost of a testing program for patients}

Effectiveness studies. The effectiveness of patient testing in preventing occupational HIV infection has not been widely studied. Some authors have evaluated the association between knowing the serological status of the patient and the rate of accidental exposure to blood among operating room personnel. In one study, no association was found between the perceived or known status of a patient and the rate of exposures (66). A similar tendency was observed in another study (67).

Apart from the identification of infected patients and the labeling of their specimens, other means of reducing the risk of HIV infection have been proposed, for example, therapeutic substitution (proposing alternative treatments to the more conventional ones) or reference to a more-experienced professional. To our knowledge, these "preventive methods" have not been studied from the point of view of effectiveness.

Cost-effectiveness studies. The cost-effectiveness ratio of a testing program aimed at patients mainly varies as a function of the prevalence and incidence of infection and of the preventive measures taken after testing. According to an American study, the cost of a mandatory testing program for all patients in a 350bed public hospital would surpass the benefits, and such a program would constitute a waste of resources (68).

In 1989 in the Province of Quebec, it was estimated that a testing program for patients admitted to acute care hospitals would cost more than $18 \mathrm{mil}-$ lion Canadian dollars (around 13 million US dollars) per year for 800000 admissions (69). This calculation reflects only a part of the real costs of such an operation since it only took into account direct costs related to the testing and counseling of hospitalized patients, excluding all those in ambulatory care or out-of-hospital settings. Other direct costs, such as those related to the infrastructure necessary to answer the incremental demand for tests, those caused by the repetition of tests, or indirect expenditures such as traveling costs or worktime lost by the individuals being tested, were not included in the calculation.

With this available evidence, systematically testing all patients appears to be an extremely expensive solution to the risk of occupational HIV transmission in health care settings. 
An alternate solution to universal testing could be selective testing of certain populations, for example, of individuals in clinical settings in which a high prevalence of HIV is expected. Thus one author found that testing clients 15 to 54 years of age (12\% of the patients admitted) upon admission to hospitals where the annual rate of AIDS diagnosis is 1 for 1000 discharges permitted the identification of twothirds of infected persons (70). We would therefore expect that a testing program directed toward a clientele selected according to certain criteria would allow HIV-infected patients to be detected more effectively and would cost less than if all patients were tested. One study looked at this question in regard to various prevalence scenarios by estimating the cost per patient tested and the cost per occupational infection prevented (71). The authors found that the additional costs related to testing hospitalized patients in the United States would amount to USD 4 billion, or USD 23000 per infected person detected if the seroprevalence rate had been $1 \%$. This cost would have been brought down to USD 14000 per patient if the prevalence had been $10 \%$, and it would have increased to USD 217000 if it had been $0.05 \%$. The additional costs for every HIV occupational infection prevented would be USD 751000 (range USD 186000 to USD 133 trillion). The author concluded that identifying infected patients with the goal of preventing occupational HIV infections would not be justified. In the same way, the Centers for Disease Control and Prevention do not recommend substituting the use of universal precautions with a testing program for patients (72).

Finally, an HIV antibody testing program for patients would be difficult to justify without including one for hepatitis B and C (73-74). Morbidity associated with hepatitis $B$, where $1 \%$ of adult cases develop a fulminant form and $10 \%$ a chronic form, with a risk of developing cirrhosis or liver cancer, would justify testing for hepatitis B as much as for HIV antibodies, at least in the absence of vaccination for all health care professionals exposed to body fluids. Furthermore, a significant chronic long-term morbidity associated with hepatitis $\mathrm{C}$ virus infection has been shown (75).

\section{Discussion}

HIV transmission in health care settings is still a matter of concern for health care workers. For some of them, the risk of infection is relatively high, notably in areas where the prevalence of HIV infection is elevated. For others, although the actual risk is low, it is perceived as being high, which can sometimes induce undesirable behavior, such as denying access to care for infected patients $(76,77)$. This worry, whether justified or not, has divided health care workers between advocates of universal and selective preventive approaches. Consequently, seven years after the Centers for Disease Control and Prevention's first recommendations on HIV preventive measures in health care settings, the situation is still confused. Anecdotal reports suggest that prevention practices in health care settings are often mixed, universal precautions having been partially implemented, whereas some professionals test patients who "look infected."

Otherwise the literature shows that universal precautions are not very concrete, as regards innumerable work situations within health care settings. This situation has brought on major differences in their interpretation and application, as shown in a study in which, although $66.4 \%$ of Canadian hospitals stated having implemented universal precautions, only $5.6 \%$ had applied all the minimal measures required by the Centers for Disease Control and Prevention (78). Moreover, the effectiveness of universal precautions in preventing bloodborne infections has not been demonstrated. Certain methodological weaknesses of evaluation studies, like the absence of a control group and poor external validity, have prevented such a demonstration.

Many health care workers do not comply with universal precautions in that they interfere with their work, are expensive, and are not very effective (29, $79,80)$. On one hand, some fail to comply systematically because they feel that they are at low risk and prefer to apply recommended measures only when they suspect a patient of being infected. On the other hand, some do not trust universal precautions and consider that testing is a more effective way to prevent HIV transmission. In fact, testing can be somewhat reassuring since it allows the hazard to be identified, necessary and perhaps extraordinary measures to be taken, and immediate knowledge of what to do in case of exposure. Testing also fits in with the tradition of infection prevention based on diagnosis.

However, as shown in the literature, HIV antibody testing of patients is not a more cost-effective solution than universal precautions, and it surely does not make sense without concurrent testing for other bloodborne infections. Moreover it is impossible to test every patient each time they consult, and the magnitude of occupational risk does not justify such expenses, while the epidemic is spreading and services to infected people are insufficient. Furthermore, such a program would considerably reduce available resources for protective equipment, and therefore render obsolete the efforts allocated to testing.

Clearly, universality of preventive measures should be maintained. It is however imperative to improve the effectiveness of these measures, particularly in the prevention of parenteral exposures, by developing safer devices and by making prevention measures "user friendly." It is also imperative to improve the cost-effectiveness of the prevention program by targeting health care settings where risk of infection is higher. 
The prerequisites for risk assessment are the knowledge of local epidemiology of the bloodborne infections included in the prevention program and knowledge of the extent of exposure to body fluids and its associated factors. As for the first prerequisite, information on infection rates in the general population is usually available through surveillance systems or prevalence studies monitoring the epidemic. As for the second, however, the epidemiology of blood and body fluid exposures is not well known mainly because of the wide variability of the information gathered by hospitals and the small size of the individual data bases not allowing in-depth analyses. Therefore there is a need to develop a standardized system of surveillance of exposures on a wide enough scale to allow the factors associated with these exposures to be identified. This step would permit more effective strategies and devices for preventing parenteral exposures to be developed, and, consequently, it should improve compliance.

Such a prevention program, based on risk assessment, is deemed necessary in most countries in the context of the financial restrictions imposed upon health care systems worldwide. Other elements, like local legislation and the already implemented preventive measures, must be accounted for in the planning process, but the magnitude of the risk of bloodborne infections for health care workers seems to us to be the main driving force in the implementation of preventive measures.

\section{References}

1. Anonymous. Needlestick transmission of HTLV-III from a patient infected in Africa. Lancet 1984;2: $1376-7$.

2. Neisson-Vernant C, Arfi S, Mathez D, Leibowitch J, Monplaisir N. Needlestick HIV seroconversion in a nurse [letter]. Lancet 1986;2:814.

3. Gioannini P, Sinicco A, Cariti G, Lucchini A, Paggi $G$, Giachino O. HIV infection acquired by a nurse. Eur J Epidemiol 1988;4:119-26.

4. Ponce de Leon RS, Sanchez-Mejorada G, Zaidi-Jackobson M. AIDS in a blood bank technician in Mexico City. Infect Control Hosp Epidemiol 1988;9:1012.

5. Looke DFM, Grove DI. Failed prophylactic zidovudine after needlestick injury [letter]. Lancet 1990;338: 884.

6. Health and Welfare Canada. A case of HIV infection possibly transmitted in an occupational setting - Ontario. Can Commun Dis Rep 1992;18:102-3.

7. Tait DR, Pudifin DJ, Gathiram V, Windson IM. HIV seroconversions in health care workers, Nathal, South Africa. Presented at the VIII International Conference on AIDS, Amsterdam, July 1992.

8. Dunn DT, Newell ML, Ades AE, Peckham CS. Risk of human immunodeficiency virus type 1 transmission through breastfeeding. Lancet 1992;340:585-8.

9. Ciesielski C, Metler R, Hammett T, Ward J. Occupationally acquired HIV infection - United States. In: Institute for Clinical and Experimental Virology of the Free University of Berlin. IXth international conference on AIDS; 1993 June 6-11. Berlin: Institute for Clinical and Experimental Virology of the Free University of Berlin, 1993:1:93.
10. Ippolito G, Puro V, De Carli G, the Italian Study Group on Occupational risk of HIV infection. Rates of HIV seroconversions by type of exposure: an update of the Italian multicentric study. In: Institute for Clinical and Experimental Virology of the Free University of Berlin. IXth international conference on AIDS; 1993 June 6-11. Berlin: Institute for Clinical and Experimental Virology of the Free University of Berlin, 1993;2:730.

11. Lot F, Abiteboul D, Bouvet E, Laporte A. Surveillance of occupationally acquired HIV infections in France. In: Institute for Clinical and Experimental Virology of the Free University of Berlin. IXth international conference on AIDS; 1993 June 6-11. Berlin: Institute for Clinical and Experimental Virology of the Free University of Berlin, 1993;2:723.

12. Perez L, Fitch K, de Andrés R, Najera R. HIV seroconversions following occupational exposure in European healthcare workers. In: Institute for Clinical and Experimental Virology of the Free University of Berlin, IXth international conference on AIDS; 1993 June 6-11. Berlin: Institute for Clinical and Experimental Virology of the Free University of Berlin, 1993;2: 724.

13. Henderson DK, Fahey BJ, Willy M, Schimitt JM, Carey K, Koziol DE, et al. Risk for occupational transmission of human immunodeficiency virus type 1 (HIV-1) associated with clinical exposures: a prospective evaluation. Ann Intern Med 1990;113:740-6.

14. Ippolito G, Puro V. De Carli G, Italian Study Group on Occupational Risk of HIV Infection. The risk of occupational human immunodeficiency virus infection in health care workers: Italian multicentric study. Arch Intern Med 1993;153:1451-8.

15. Kiyosawa K, Sodeyama T, Tanaka E, Nakano Y, Furata $S$, Nishioka $K$, et al. Hepatitis $C$ in hospital employees with needlestick injuries. Ann Intern Med 1991;115:367-9.

16. Schlipköter U. Transmission of hepatitis $C$ virus (HCV) from a haemodialysis patient to a medical staff member. Scand J Infect Dis 1990;22:757-8.

17. Mayo-Smith MF. Type non-A, non-B and type B hepatitis transmitted by a single needlestick. Am J Infect Control 1987; 15:266-7.

18. Seeff LB. Hepatitis C from a needlestick injury. Ann Intern Med 1991;115:411.

19. Ahtone J, Francis D, Bradley D, Maynard J. Non-A, non-B hepatitis in a nurse after percutaneous needle exposure [letter]. Lancet 1980;1:1142.

20. Lim WL, Yeoh EK. Occupationally acquired hepatitis C virus infection. Lancet 1992;339:304-5.

21. Mitsui T, Iwano K, Masuko K, Yamazaki C, Okamoto $H$, Tsuda $F$, et al. Hepatitis $C$ virus infection in medical personnel after needlestick accident. Hepatology 1992;16:1109-14.

22. Howard RJ. Human immunodeficiency virus testing and the risk to the surgeon of acquiring HIV. Gynecol Obstet 1990;171:22-6.

23. Gerberding JL. Does knowledge of human immunodeficiency virus infection decrease the frequency of occupational exposure to blood? Am J Med 1991;91 suppl 3B:308S-11S.

24. Centers for Disease Control. Recommendations for prevention of HIV transmission in health-care settings. MMWR 1987;36 suppl 2S;1S-18S.

25. Centers for Disease Control. Guidelines for prevention of transmission of human immunodeficiency virus and hepatitis B virus to health-care and public-safety workers. MMWR 1989;38.

26. Dajczman E, Dascal A, Orenstein P, Frank H. Survey of infection control precautions: a comparison to recommended guidelines. Can J Infect Control 1992;7: $7-12$.

27. Naccache H, Fortin C, Croteau A, Godin G. Univer- 
sal precautions in a teaching hospital: compliance and perception. AIDS Pat Care 1993;7:134-7.

28. Brattebo G, Wisborg T, Sjursen $\mathrm{H}$. Health workers and the human immunodeficiency virus: knowledge, ignorance and behavior. Public Health 1990;104:123-30.

29. Kelen GD, DiGiovanna TA, Celentano DD, Kalainov D, Bisson L, Junkins E, et al. Adherence to universal (barrier) precautions during interventions on critically ill and injured emergency department patients. J Acquired Immune Defic Syndrome 1990;3:987-94.

30. Talan DS, Baraff LJ. Effect of education on the use of universal precautions in a university hospital emergency department. Ann Emerg Med 1990;19:1322_6.

31. Elford J, Cockcroft A. Compulsory HIV antibody testing, universal precautions and the perceived risk of HIV: a survey among medical students and consultant staff at a London teaching hospital. AIDS Care 1991;3:151-8.

32. Ros SP, Cabrera-Ros BL. Poor compliance with universal precautions: a universal phenomenon? Pediatr Emerg Care 1990;6:183-5.

33. Baraff LJ, Talan DA. Compliance with universal precautions in a university hospital emergency department. Ann Emerg Med 1989;18:654-7.

34. Hellgren K. Use of gloves among dentists in Sweden. Swed Dent J 1990;14:137-42.

35. Smyser MS, Bryce J, Joseph JG. AIDS-related knowledge, attitudes and precautionary behaviors among emergency medical professionals. Public Health Rep 1990;105:496-503.

36. Kaczmarek RG, Moore RM, McCrohan J, Arrowsmith-Lowe JT, Caquelin C, Reynolds C, et al. Glove use by health care workers: results of a tristate investigation. Am J Infect Control 1991;19:228 - 32.

37. Hammond JS, Eckes JM, Gomez GA, Cunningham DN. HIV, trauma, and infection control: universal precautions are universally ignored. J Trauma 1990;30: $555-61$.

38. Becker MH, Janz NK, Band J, Bartley J, Snyder MB, Gaynes RP. Noncompliance with universal precautions policy: why do physicians and nurses recap needles? Am J Infect Control 1990;18:232-9.

39. Fahey BJ, Koziol DE, Banks SM, Henderson DK. Frequency of non parenteral occupational exposures to blood and body fluids before and after universal precautions training. Am J Med 1990;90:145-153.

40. Wong ES, Stotka JL, Chinchili VM, Williams DS, Stuart CG, Markowitz SM. Are universal precautions effective in reducing the number of occupational exposures among health care workers? JAMA 1991;265: 1123-1128.

41. Ribner BS, Landry MN, Gholson GL, Linden LA. Impact of a rigid, puncture resistant container system upon needlestick injuries. Infect Control 1987;8:6366.

42. Krasinsky K, LaCouture R, Holzman RS. Effect of changing needle disposal systems on needle puncture injuries. Infect Control 1987;8:59-62.

43. Edmond M, Khakoo R, McTaggart Bonny, Solomon $R$. Effect of bedside needle disposal units on needle recapping frequency and needlestick injury. Infect Control Hosp Epidemiol 1988;9:114 -6.

44. Smith DA, Eisenstein HC, Esrig C, Godbold J. Constant incidence rates of needle-stick injury paradoxically suggest modest preventive effect of sharps disposal system. J Occup Med 1992;34:546-51.

45. Linnemann CC, Cannon C, DeRonde M, Lanphear B. Effect of educational programs, rigid sharps containers, and universal precautions on reported needlestick injuries in healthcare workers. Infect Control Hosp Epidemiol 1991;12:214-9.

46. Nichols RL. Barrier efficiency of surgical drapes and isolation gowns. In: Centers for Disease Control. 5th national forum on AIDS, hepatitis, and other bloodborne diseases, 1992 Mar29-Apr1. Atlanta, GA: Symedco, 1992:46.

47. Telford $G$, Quebbeman EJ. In-use evaluation of surgical gowns: a prospective trial. In: Centers for Disease Control. 5th national forum on AIDS, hepatitis, and other blood-borne diseases, 1992 Mar29-Apr1. Atlanta, GA: Symedco, 1992:46.

48. Lovitt SA, Smith JW, Muzik AC, Pearce PR, Nichols RL. Isolation gowns: a false sense of security? In: Centers for Disease Control. 5th national forum on AIDS, hepatitis, and other blood-borne diseases, 1992 Mar29_Apr1. Atlanta, GA: Symedco, 1992:47.

49. Jagger J, Pearson RD. Do universal precautions reduce needlestick injuries? JAMA 1991;266:3:359-60.

50. Chiarello LA, Nagin DS, Kowalski E. Evaluation of needlestick prevention devices in ten New York state (NYS) hospitals. In: US Department of Health and Human Services, US Department of Labor. A national conference on prevention of device-mediated bloodborne infections, 1992 Aug 17-19. Washington, DC: US Department of Health and Human Services, US Department of Labor, 1992:30.

51. Doebbeling BN, Wenzel RP. The direct costs of universal precautions in a teaching hospital. JAMA 1990; 264:2083-7.

52. Stock SR, Gafni A, Bloch RF. Universal precautions to prevent HIV transmission to health care workers: an economic analysis. Can Med Assoc J 1990;142: $937-6$.

53. Garner JS. Universal precautions and isolation systems. In: Bennett JV, Brachman PS, editors. Hospital infections. Boston, MA: Little, Brown, 1992:241 -2.

54. Lynch P, Jackson MM, Cummings MJ, Stamm WE. Rethinking the role of isolation practices in the prevention of nosocomial infections. Ann Intern Med 1987; 107:243-6.

55. Jackson MM, Lynch P, McPherson DC, Cummings MJ, Greenawalt NC. Why not treat all body substances as infectious. Am J Nurs 1987;87:1137-9.

56. Gerberding JL. Reducing occupational risk of HIV. Hosp Pract 1991;26:103(10):115-8.

57. Lynch P, Cummings MJ, Roberts PL, Herriot MJ, Yates B, Stamm WE. Implementing and evaluating a system of generic infection precautions: body substance isolation. Am J Infect Control 1990;18:1-12.

58. Troya SH, Jackson MM, Lovrich-Kerr M, McPherson DC. A survey of nurses' knowledge, opinions, and reported uses of the body substance isolation system. Am J Infect Control 1991;19:268 - 76.

59. Board of Trustees, American Medical Association. Prevention and control of acquired immunodeficiency syndrome. JAMA 1987;258:2097-103.

60. Rhame FS, Maki DG. The case for wider use of testing for HIV infection. N Engl J Med 1989;320:124854.

61. Angell M. A dual approach to the AIDS epidemic. $N$ Engl J Med 1991;324:1498-500.

62. Canadian Task Force on the Periodic Health Examination. Periodic health examination, 1992 update: 3. HIV antibody screening. Can Med Assoc J 1992;147: $867-76$.

63. Urassa WK, Bredberg-Raden U, Mbena E, Palsson K, Minja E, Lema RA, et al. Alternative confirmatory strategies in HIV-1 antibody testing. J Acquired Immune Defic Syndrome 1992;5:170-6.

64. Behets F, Bishagara K, Disasi A, Likin S, Ryder RW, Brown C, et al. Diagnosis of HIV infection with instrument-free assays as an alternative to the ELISA and Western Blot testing strategy: an evaluation in Central Africa. J Acquired Immune Defic Syndrome 1992; 5:878-82.

65. Bayer R. Public health policy and the AIDS epidemic, an end to HIV exceptionalism? N Engl J Med 1991; 
$324: 1500-2$.

66. Gerberding JL, Littel C, Tarkington A, Brown A, Schecter WP. Risk of exposure of surgical personnel to patients' blood during surgery at San Francisco General Hospital. N Engl J Med 1990;322:1788-93.

67. Tokars JI, Bell DM, Culver DH, Marcus R, Mendelson $\mathrm{MH}$, Sloan EP. Percutaneous injuries during surgical procedures. JAMA 1992;267:2899-904.

68. La Croix S, Russo G. Costs and benefits of mandatory HIV testing for healthcare workers and hospital patients. In: Harvard University, Dutch Foundation AIDS Conference, editors. VIII international conference on AIDS/III STD world congress; 1992 Jul 19-24. Amsterdam: CONGREX Holland BV, 1992:D463.

69. Roy É, Desjardins J, Lauzon D. Virus de l'immunodéficience humaine et retrait préventif de la travailleuse enceinte ou qui allaite. Québec: Comité provincial en santé au travail du Québec, 1989.

70. Janssen RS, St-Louis ME, Satten GA, Critchley SE, Petersen LR, Stafford RS, et al. HIV infection among patients in US acute care hospitals, strategies for counselling and testing of hospital patients. N Engl J Med 1992:327;445-52.

71. Lurie P, Avins AL, Phillips KA, Kahn JG, Lowe RA, Franks P, et al. Routine HIV testing of inpatients: costs, benefits, and problems. In: Institute for Clinical and Experimental Virology of the Free University of Berlin. IXth international conference on AIDS; 1993 June $6-11$. Berlin: Institute for Clinical and Experimental Virology of the Free University of Berlin, 1993;1:97.

72. Centers for Disease Control and Prevention. Recommendations for HIV testing services for inpatients and outpatients in acute-care hospital settings. MMWR 1993;42:1-6.

73. Gordin FM, Gibert C, Hawley HP, Willoughby A. Prevalence of human immunodeficiency virus and hepatitis $B$ virus in unselected hospital admissions: implications for mandatory testing and universal precautions. J Infect Dis 1990:161;14-7.
74. Kelen GD, Green GB, Purcell RH, Chan DW, Qaqish BF, Sivertson KT, et al. Hepatitis B and hepatitis C in emergency department patients. N Engl J Med 1992; 326:1399-404.

75. Kaklamani E, Trichopoulos D, Tzonou A, Zavitsanos X, Koumantaki Y, Hatzakis A, et al. Hepatitis B and $\mathrm{C}$ viruses and their interaction in the origin of hepatocellular carcinoma. JAMA 1991;265:1974-6.

76. Yagi S, Yagi A, Takahashi T, Kikushi S. How AIDS is perceived by nurses and health care workers in Daini Hospital, Nippon Medical School. In: Institute for Clinical and Experimental Virology of the Free University of Berlin. IXth International Conference on AIDS; 1993 June 6-11. Berlin: Institute for Clinical and Experimental Virology of the Free University of Berlin, 1993;2:1891.

77. Bresolin L, Rinaldi R, Hemming J, Gans J. A national survey of 4000 physicians. In: International Institute for Clinical and Experimental Virology of the Free University of Berlin. IXth international conference on AIDS; 1993 June 6-11. Berlin: Institute for Clinical and Experimental Virology of the Free University of Berlin, 1993;2:894.

78. Birnbaum D, Schulzer M, Mathias RG, Kelly M, Chow AW. Adoption of guidelines for universal precautions and body substance isolation in canadian acute-care hospitals. Infect Control Hosp Epidemiol 1990;11: $465-72$.

79. Courington KR, Patterson SL, Howard RJ. Universal precautions are not universally followed. Arch Surg 1991;126:93-6.

80. Gruber M, Beavers FE, Johnson B, Brackett M, Lopez T, Feldman MJ, Ventura M. The relationship between knowledge about acquired immunodeficiency syndrome and the implementation of universal precautions by registered nurses. Clin Nurse Spec 1989;3:1825 .

Received for publication: 2 February 1994 